\title{
Petrographic and mineralogic investigations of heated basalt aggregate concrete.
}

\author{
Hafez. S. Abdelwahab ${ }^{1}$, Nasser. G. Abdel Ghafour ${ }^{2}$ and Mohamed. E.Taha ${ }^{2}$ \\ ${ }^{1}$ Faculty of Science, Ain Shams University, Cairo, Egypt) \\ ${ }^{2}$ (Housing and Building National Research Center, Cairo, Egypt)
}

\begin{abstract}
The present study is mainly devoted to focus on the effect of elevated temperature on concrete properties and micro structure to avoid as possible as we can the various undesired effects of the severe environmental impacts, which affect the service life of concrete. The concrete casted with basalt aggregate was subjected to elevated temperatures $\left(300,600, \& 800^{\circ} \mathrm{C}\right)$ with a rate of $5^{\circ} \mathrm{C} / \mathrm{min}$, and an exposure time of two hours. Furthermore, the obtained results showed that the mechanical properties of the heated concrete, associated with the internally induced chemical changes are attributed to temperature elevation effect. Both laboratorial investigations and mineralogic study revealed by using reflected light microscopic study on polished slabs, SEM investigation, confirmed the effect of elevated temperatures on cement paste and aggregates.
\end{abstract}

Keywords: Concrete, Basalt aggregate, Elevated temperatures, Mechanical properties, reflected light, polished slabs, SEM.

\section{Introduction}

Under normal conditions, most of concrete structures are subjected to temperature variations of ambient environmental conditions. However, there are exceptional cases, where concrete may be subjected to higher temperatures (e.g., building fires, chemical and industrial firms in which the concrete occurs in a close proximity to furnaces), and hence some drastic changes may occur.

Exposure of concrete to elevated temperature affects its mechanical and physical properties. The changes in properties result from three main processes that take place at elevated temperature: (1) phase transformations (e.g., loss of free water at about $100^{\circ} \mathrm{C}$, decomposition of calcium hydroxide at about $450^{\circ} \mathrm{C}$, and crystal transformation of quartz at $573^{\circ} \mathrm{C}$ from alpha to beta form, (2) pore structure evolution (e.g., volumes and surfaces of pores increase until reaching temperature of about $500^{\circ} \mathrm{C}$, and then decreases with increasing temperature degrees, and (3) coupled thermo-hygro-chemo-mechanical processes (e.g., temperature gradients leading to thermal stresses, multiphase transport of water, and chemical changes that affect pore pressure and structure) [1].

In the present study, the primary target is to investigate the physico-mechanical and micro structural changes associated with chemical transformation, which took place in the laboratorial casted basalt aggregate concrete components. This happened during subjection to various degrees of heating, in order to record the changes in mechanical properties emphasized by residual compressive strength value and micro structure features of concrete. As reported before in the present study, normal concrete loses about $30 \%$ of its compressive strength, when heated up to $300^{\circ} \mathrm{C}$ and about $70 \%$ when heated up to $800^{\circ} \mathrm{C}$ [2].

The fluorescent reflected-light microscopy examination of fluorescent dyed polished sections by using stereomicroscope illustrated all the original voids (air voids, capillary pores in paste, cracks, and aggregate porosities) [3].

SEM study as a supplementary tool, beside the petrographic examination helped to shed the light on the micro structure changes in details. SEM carried out on polished concrete slabs was used to generate the backscattered electron image (BSE) of polished flat surface, with 256 'gray levels' resulted from variation in backscatter intensity with atomic number. This backscattered electron images was useful to characterize the multi component materials in cement paste and aggregates, and hence the heavier atoms will give backscatter more electrons than lighter one, thus producing more brighter gray tones in the images than those of the less dense materials [4].

\section{Material and laboratorial studies}

\section{Experimental work}

Ordinary Portland cement complying with ESS 4756-1 [5], having a content of $325 \mathrm{~kg} / \mathrm{m}^{3}$ was used for concrete mix preparation. The used concrete fine aggregate fraction is the natural siliceous river sand, while the coarse aggregate fraction was prepared by crushing basalt picked from stock piles of Widan El-Faras quarries located at Fayium governorate at latitude $29^{\circ} 39^{\prime} 57.80^{\prime \prime}$ and longitude $30^{\circ} 36^{\prime} 50.33^{\prime \prime}$. The preparation 
carefully considered regarding grading that confirms with ASTM C136 [6]. In the hand specimens, basalt aggregate appears dark black in colour with a slight alteration (reddish brown) on the exposed surface. This is a visible sign which indicates that basalt is slightly weathered. Two sizes of coarse aggregate fractions $12.5 \& 19$ $\mathrm{mm}$ were mixed with equal amounts, together with sand and cement, to prepare the desired concrete mix. The mixing water used during the preparation of the concrete specimens, was the tap water.

As shown in Table 1, an arbitrary concrete mix of ratio $1: 2: 4$ (being the proportion of cement: fine aggregate: coarse aggregate) with water/cement ratio 0.55 . The casting of concrete was commenced in cubic steel moulds with dimension of $10 \mathrm{~cm}$.

Table 1: Concrete mix proportions.

\begin{tabular}{|c|c|c|c|c|c|}
\hline \multirow[t]{2}{*}{ Mix } & \multirow{2}{*}{$\begin{array}{c}\text { Cement } \\
\text { content, } \\
\mathbf{k g} / \mathbf{m}^{3}\end{array}$} & \multirow{2}{*}{$\begin{array}{c}\text { Water } \\
\text { content } \\
\mathrm{kg} / \mathrm{m}^{3}\end{array}$} & \multirow{2}{*}{$\begin{array}{l}\text { Fine aggregate } \\
\text { content } \\
\mathbf{K g} / \mathbf{m}^{3}\end{array}$} & \multicolumn{2}{|c|}{$\begin{array}{c}\text { Coarse aggregate } \\
\text { content } \mathrm{Kg} / \mathrm{m}^{3}\end{array}$} \\
\hline & & & & $12.5 \mathrm{~mm}$ & $19 \mathrm{~mm}$ \\
\hline Bs & 325 & 178.75 & 650 & 650 & 650 \\
\hline
\end{tabular}

\section{Curing and heating cycle}

The concrete specimens casted in cubic moulds were demoulded after 24 hours of casting and placed in a water tank at $20^{\circ} \mathrm{C}$, after 28 days of water curing, these cubes were oven dried to $105^{\circ} \mathrm{C}$ to a constant weight. The dried specimens were then heated in an electric furnace with a rate of $5^{\circ} \mathrm{C} /$ minute to 300,600 , and $800^{\circ} \mathrm{C}$, with an exposure time of two hours. The specimens were then allowed to cool down to room temperature and loaded to failure. Furthermore, a specimen representing each temperature range was selected to prepare polished sections for the petrographic investigation.

\section{Methods}

The compressive strength test was performed according to ESS 203-3 [7] using uniaxial compression instrument with a capacity of $15 \mathrm{KN}$, and a loading rate of $5 \mathrm{Kg} / \mathrm{cm}^{2}$. The compressive strength test was carried out on the concrete specimens after exposure to elevated temperatures, and leaving the specimens to cool to the ambient temperature. Representative specimens from each temperature were used for the test. The average of two measurements was recorded and compared with the compressive strength of the 28 days cured unheated concrete, as a reference specimen for calculating the residual compressive strength in percentage.

Petrographic examination was performed on concrete cubes which are collected from dried water cured and heated concrete samples to 300,600 , and $800^{\circ} \mathrm{C}$. Each cube representing the examined case is split into two halves; one half is used for preparation of fluorescent dyed flat polished sections for stereomicroscope examination and the other half is devoted for SEM investigation.

In order to produce a flat polished section of concrete specimen, a flat slab (size $50 * 50 * 10 \mathrm{~mm}$ ) is cut from examined concrete specimen, using a diamond saw and non hydrated lubricating media (Propylene glycol), and was consolidated by vacuum impregnation by using a low viscous fluorescent epoxy resin, to preserve the sample components and to keep the microstructural features. The slab is then lapped by using a series of silicon carbide grit Nos. $100(122 \mu \mathrm{m}), 220(63 \mu \mathrm{m}), 320(31 \mu \mathrm{m})$, and $600(16 \mu \mathrm{m})$, each grit lasted for about 2 minutes. Finally, the sections were polished by diamond paste, until a smooth surface free from defects of sawing is obtained for examinations.

The investigation of fluorescent dyed flat polished concrete was performed under UV light by using fluorescent reflected-light microscopic examination (Olympus Gx70) equipped with a blue filter (BG-12). The examination of fluorescent concrete polished slabs was carried out under magnification 50X.

Scanning electron examination was performed on the second flat epoxy impregnated polished slabs, which was cut from concrete cubes, to produce a backscattered electron image (BSE), using Inspect S SEM (FEI Company, Netherland) with an operating voltage of $25 \mathrm{kV}$ and magnification of $100 \mathrm{X}$.

\section{Results And Discussion}

Because compressive strength is one of the prime qualities by which concrete is judged, thus it may be considered the most investigated property at high temperature. It is widely accepted that the concrete residual strength can be used as a significant indication for the damages sustained during fires for high temperatures [8]. As shown in Fig. 1, the residual compressive strength of the heated concrete specimens ratio compared to the strength of 28 days cured specimen before heat exposure, it is observed that the heated concrete retained 80, 75, and $37 \%$ of the original value corresponding to 300,600 , and $800^{\circ} \mathrm{C}$ respectively. The significant strength loss at $800^{\circ} \mathrm{C}$ is mainly attributed to decomposition of calcium silicate hydrate gel (CSH) [9]. 


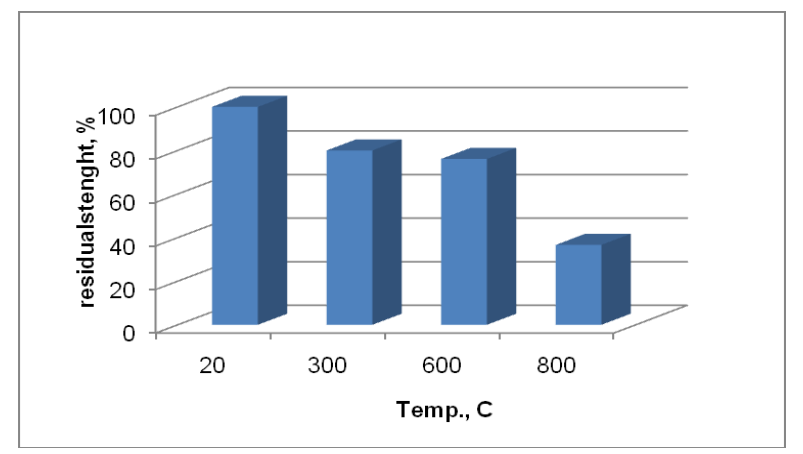

Fig. 1: Residual compressive strength of concrete specimens subjected to elevated temperature.

The present study confirms that the fluorescence impregnated slabs are useful in determining the extent of the damage attributed to the elevated temperatures, as it highlight the cracks whose width is below the resolving power of the lenses used in normal optical microscopy [10]. Microscopic study demonstrates that the variation in paste porosity can be determined from the variation in the fluorescence degree, the porous areas in the paste appear in a light green colour, whereas, the denser areas appear in a darker green colour. The concrete at ambient temperature examined under fluorescent light is shown in Fig. 2(a). The observed green colour in the bulk of the cement paste $(\mathrm{Cp})$ is darker than that in the voids $(\mathrm{V})$ and interfacial transitional zone (ITZ) around the fine and coarse aggregate grains, thus indicating a higher porosity. Also, the basalt grains (Bs) appear black, while the sand grains appear translucent. Moreover, a transverse crack $(\mathrm{Cr})$ which is observed in the coarse basalt aggregate indicates a zone of weakness due to weathering effect. The examination of concrete heated to $300^{\circ} \mathrm{C}$ using fluorescent light, as shown in Fig. 2(b), reveals that the free water evaporates [1] turning the whole cement paste into a light green colour.

The examined concrete heated to $600^{\circ} \mathrm{C}$ using fluorescent light, shows an increase in the crack magnitude, within the basalt aggregate and in the cement paste as shown in Fig. 2(c). These cracks developed in the cement paste with the light green colour, are actually attributed to the dissociation of calcium hydroxide and the expansion of quartz grains. On the other hand, the concrete heated to $800^{\circ} \mathrm{C}$, as shown in Fig. 2(d), demonstrates that the cement paste appear in a very light green colour in some areas, as compared to the other temperatures, which is mainly attributed to decomposition of calcium silicate hydrate gel (CSH) of the cement.
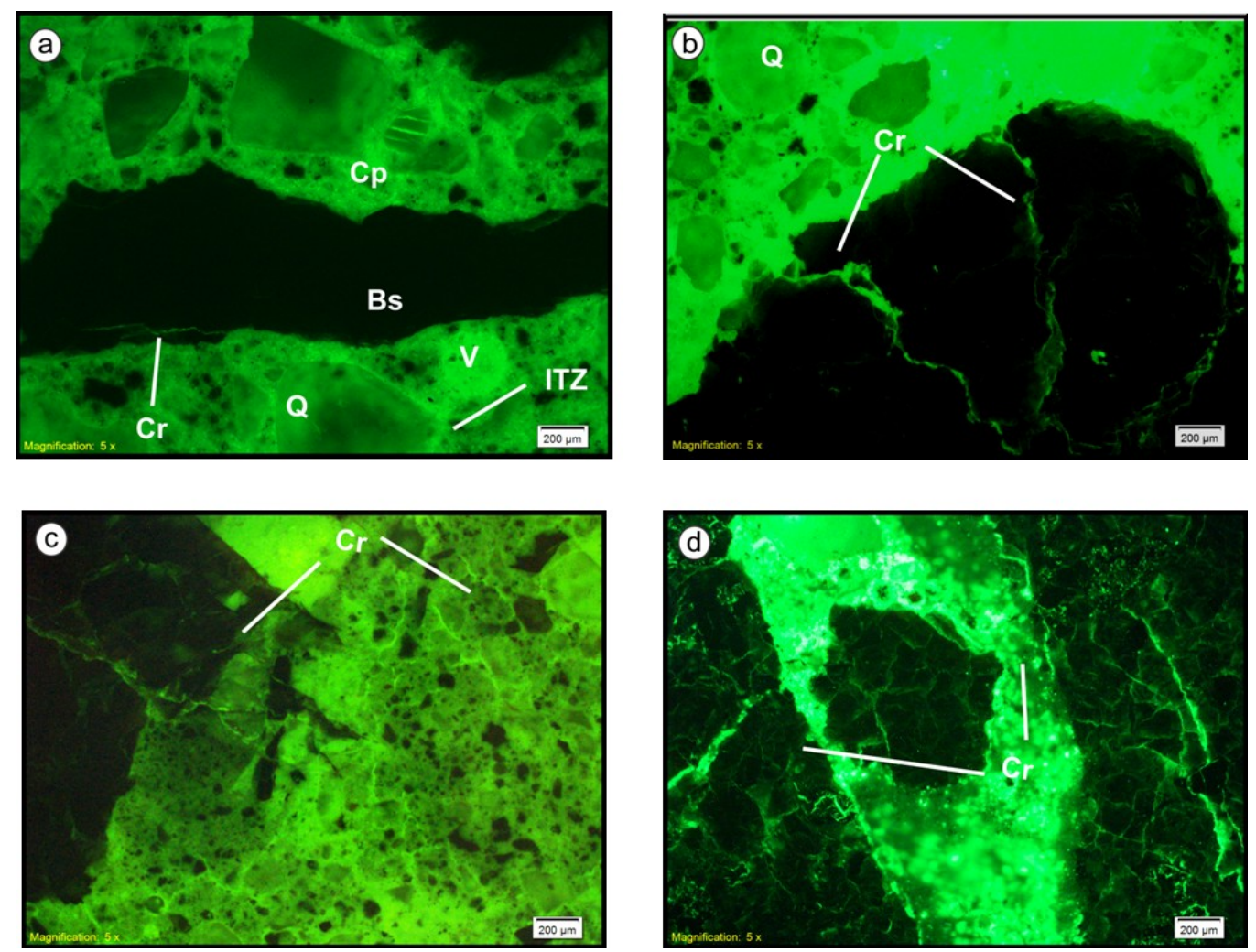

Fig. (2): Fluorescent photomicrographs of basalt aggregate concrete specimens: a) unheated b) heated to $300^{\circ} \mathrm{C} \mathrm{c}$ ) heated to $600^{\circ} \mathrm{C}$ d) heated to $800^{\circ} \mathrm{C}$. 
Petographically Widan el-Faras basalt consists mainly of plagioclase feldspar (Pl), pyroxene (Pyx) and a volcanic glass, with a minor amount of opaque constituents as magnetite (Ma) and rarely quartz (Q). The brownish colour of the exposed surface of basalt aggregate is attributed to devitrification of basaltic glass [11].

The SEM-backscattered electron (BSE) micrographs of the surface micro structure of concrete specimens are shown in Fig. 3, the examined concrete representing the ambient temperature as shown in Fig. 3(a), shows the typical concrete micro structure with abundant hydrated phase as calcium silicate hydrate and calcium hydroxide as main components of cement paste (Cp), unhydrated cement phases (B), fine aggregate of sand grains $(\mathrm{Q})$ and coarse aggregate of basalt grains (Bs), as well as the interfacial transitional zone (ITZ), which is reported to be the weakest bond and most porous zone in the cement paste, due to calcium hydroxide concentration [12]. However, concrete back scattered micrograph of concrete specimen heated to $300^{\circ} \mathrm{C}$, as shown in Fig. 3(b), indicates a good bonding along the aggregate/cement paste interface (interfacial transitional zone) and the development of a few micro cracks within the basalt aggregates, that propagate into the plagioclase within the matrix.

On the other hand, the backscattered micrograph of concrete specimens heated to $600^{\circ} \mathrm{C}$, as shown in Fig. 3(c), indicates the development of two types of cracks; these are cracks developed around aggregates (interfacial cracks) and cracks developed in the cement paste (cement paste cracks). The interfacial cracks are developed around the quartz grains and propagate into the cement paste are explained to be due to crystal transformations, thus leading to significant increase in the volume [e.g., crystalline transformation of $\alpha$-quartz (trigonal) to $\beta$-quartz (hexagonal) between $500^{\circ} \mathrm{C}$ and $650^{\circ} \mathrm{C}$, with an accompanying increasing in volume of $\sim 5.7 \%]$, [13].

The cracks developed around the coarse aggregate grains are actually attributed to the thermal incompatibility between the cement paste and the aggregate. Also the depletion of the hydration products is attributed to dissociation of calcium hydroxide that spread between $400^{\circ} \mathrm{C}$ and $600^{\circ} \mathrm{C}$, and consequently led to a significant strength reduction [14]. Furthermore, the backscattered electron micrograph of concrete specimen heated to $800^{\circ} \mathrm{C}$, as shown in Fig. 3(d), these indicate the development of three types of cracks; these are cracks around the coarse aggregate and fine aggregate, cracks in the cement paste and within the coarse aggregate. The cracks developed within basalt are believed to be due to presence clay minerals, which present as weathering products in basalt. Moreover, it is noticed that the increase in dimensions and frequencies of cracks, which renders the concrete to become structurally unuseful at this temperature. This is confirmed by the very low residual compressive strength value.

\section{Conclusions}

1- The mechanical properties of the concrete are highly affected by the impact of elevated temperature; this is indicated by the residual strength values for each temperature. This is recorded to each temperature. The residual strength values of concrete heated to $300^{\circ} \mathrm{C}$ and $600^{\circ} \mathrm{C}$ proved that the concrete is still structurally useful, while the concrete heated to $800^{\circ} \mathrm{C}$ was totally unuseful structurally.

2 - The examination of fluorescent dyed flat slabs of heated concrete specimens revealed that the chemical and physical changes accruing in the cement paste and aggregate can be sensed through the change in degree of fluorescence around the ITZ, in the cement paste and within the aggregate itself. Thus, it can be deduced that the ITZ was intact up to $300^{\circ} \mathrm{C}$. On the contrary, the ITZ at $600^{\circ} \mathrm{C}$ and $800^{\circ} \mathrm{C}$ begin to debond, leading to the development of interfacial cracks and cement paste cracks, and thus yielding a significant strength loss.

3 - The SEM-BSE investigations of microstructural features changes visually from micrograph of heated concrete at different temperatures was very effective in indication of aggregate expansions, crack extents and frequency, as well as cement paste deterioration signs. 

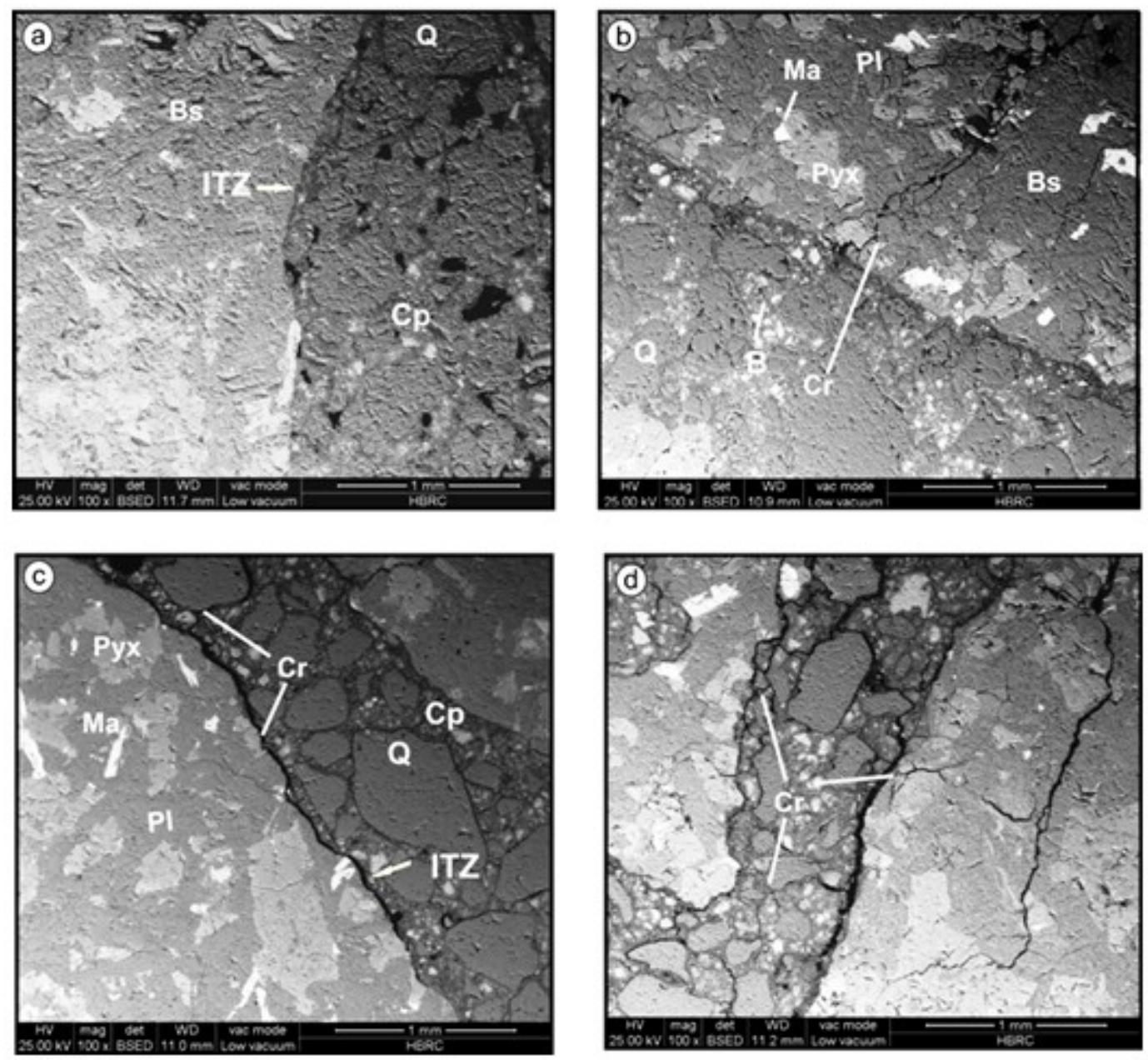

Fig. (3): BSE micrographs showing micro structure of basalt aggregate concrete specimens: a) unheated b) heated to $300^{\circ} \mathrm{C} \mathrm{c}$ ) heated to $600^{\circ} \mathrm{C}$ d) heated to $800^{\circ} \mathrm{C}$.

\section{References}

[1]. K. Willam, and I. Rhee, Thermal Degradation Effects in Concrete Material Systems, NSF-FHWA workshop on imaging and simulation of concrete structures, Northwestern Univ., Evanston, Illinois, USA, 2003.

[2]. F. A. Aly, D. O. Connor, and A. Abu Tair, Explosive spalling of high strength concrete columns in fire, Mag. of Conc. Res., Vol. 53, No. 3, 2001, PP. 197-204.

[3]. P. K. Mehta, Durability of Concrete in Marine Environment - A Review, performance of concrete in marine environment, V. M. Malhotra ed., ACI SP-65, 1980, PP. 1-19.

[4]. I. M. Watt, The principals and Practice of Electron Microscopy $\left(2^{\text {nd }}\right.$ edn. Cambridge Univ. Press, Britain, Uk, 1997).

[5]. ESS 4756-1, Egyptian Standard Specification for Composition, Requirements and Conformity standard for common cements, part $1,2009$.

[6]. ASTM C136, Standard Test Method for Sieve Analysis of Fine and Coarse Aggregates. Annual book of ASTM Standards, Philadelphia, USA, Vol. 04.02.

[7]. ESS 203-3, Egyptian Standard Specification for Execution and Designing of concrete building: laboratory testing for concrete material, Egypt, 2009.

[8]. A. E. Ahmed, A. H. Al-Shaikh, and T. I. Arafat, Residual compressive and bond strength of limestone aggregate concrete subjected to elevated temperatures. Mag. Concr. Res. Vol. 44 (161), 1992, PP. 117-125.

[9]. X. Y. Wong, C. S. Poon, and M. Anson, Impact of high temperature on PFA concrete. Mag. Cem. Concr. Res., Vol. 31, 2001 , PP. $1065-1073$.

[10]. Petrographic Methods of Examining Hardened Concrete, A Petrographic Manual, Pub. No. FHWA-HRT-04-150, Virginia transportation research council, department of transportation, USA, 2006.

[11]. T. P. Nicholshon, and I. Shaw, Ancient Egyptian Materials and Technology (Cambridge University Press, Cambridge, Uk, 2000).

[12]. Fire Design of Concrete Structures-Materials, Structures and Modelling, State of art report, Fib Bull. 38, 2007 pp $65-67$.

[13]. T. W. kennedy, An evaluation and summary of a study on the long-term multiaxial creep behavior of concrete, Res. Report 3899-2, department of civil engineering, The univ. of Texas at Austin, USA, 1975.

[14]. E. Annerel, and L. Taerwe, Revealing the temperature history in concrete after fire exposure by microscopic analysis, Mag. Cem. and Concr. Res., Vol. 39, 2009 PP. 1239-1249. 